and Choroidal Diseases had been published, and he had completed 8 chapters and blocked the headings of the remainder of the second volume. Desmond Archer then took on the responsibility for completing the volume, and he and August Deutman ( 2 of his dedicated coworkers) wrote the bulk of the unfinished chapters.

The book is an admirable memorial to Alex Krill, who is missed by all who knew him. Each chapter is written with extreme thoroughness and is exceptionally well referenced. One cannot help but admire the level of scholarship that has been devoted to the completion of this book. It is ideally suited as a reference book for any research worker interested in hereditary fundus diseases, the illustrations are extremely good, and yet the book is eminently readable. I would recommend this book to anyone who is working in this field or to any practitioner who wants a volume with up-to-date information on hereditary retinal and choroidal diseases.

A. C. BIRD

\title{
Correspondence
}

\section{Long-term results of Choyce anterior chamber lens implants}

TO THE EDITOR, British Journal of Ophthalmology

SIR, I am grateful to Mr J. L. Pearce for finding the time and taking the trouble to examine my patients in 1971 and to write the paper which you, Sir, were good enough to publish (Pearce, 1975). On p. 101, under the heading 'Less serious corneal changes', Mr Pearce lists 9 cases $(13.2 \%)$ exhibiting areas of corneal oedema mainly in relation to the feet of the implant, illustrated by a figure on p. 102. Mr Pearce expressed the opinion that with the passage of time these changes could progress to frank corneal decompensation, thus increasing the incidence of bullous keratopathy, which he found to be $1.5 \%$.

Nowadays I am often questioned about the subsequent fate of these 9 patients. The facts are that 2 died within a year of their examination by Mr Pearce with their corneal pathology and visual acuity unchanged. The other 7 have all been examined within the last 6 months, and their acuity and corneal status are also unchanged.

\section{Treatment with urokinase}

TO THE EDITOR, British Journal of Ophthalmology

SIR, I would like to clarify certain remarks concerning our intravitreal injection technique as mentioned in your excellent Editorial (1977). The statement that in earlier reports up to $1.5 \mathrm{ml}$ of vitreous was aspirated before injection of urokinase in an equal amount of water has been referenced to our paper (Dugmore and Raichand, 1973) by mistake. We had, in fact, described aspiration of only $0.5 \mathrm{ml}$ of vitreous. I hope that the following explanation will rectify certain statements in your Editorial.

As we were the first investigators to study the role of intravitreal urokinase in the treatment of vitreous haemorrhage (Raichand, 1970), we had to develop our own technique for the study. After evolving our technique in animal eyes, in February 1971, we performed the first intravitreal injection of urokinase in a human eye (Raichand, 1971a, b). Evaluation of intravitreal urokinase was done in 1970 (Raichand, 1970) when intravitreal techniques and vitreous surgery were in their infancy.
Their average age is now 76 , and the average time since implantation is 12 years 8 months.

I have inserted approximately $1000 \mathrm{Mk}$ VIII anterior chamber implants since the end of 1963, and my experience is that if corneal decompensation is going to occur it does so within 12 months of insertion and only rarely after longer periods of time. Yours faithfully, D. P. CHOYCE

9 Drake Road, Westcliff-on-Sea, Essex SS0 8LR

\section{Reference}

Pearce, J. L. (1975). Long-term results of the Choyce anterior chamber lens implants Marks V, VII, and VIII. British Journal of Ophthalmology, 59, 99-106.

Since then the development of vitrectomy techniques has revolutionised the treatment of vitreous haemorrhage.

Contrary to the statement in your Editorial, it was a Glasgow report (Williamson and Forrester, 1972) that described intravitreal injection of $1.5 \mathrm{ml}$ of urokinase without aspiration of vitreous or aqueous. We (Dugmore and Raichand, 1972) promptly questioned this report, for we were aware that technically this was impossible, and, if a large amount $(1.5 \mathrm{ml})$ of vitreous was aspirated, improvement in visual acuity could also be attributed to this element of vitreous 'exchange'.

From our animal studies we had realised that it is practically impossible to inject even small quantities of urokinase in the eye without raising the intraocular pressure to a very high level and developing a severe reaction in the anterior chamber. Even anterior chamber paracentesis did not reduce the severe anterior chamber reaction; moreover, the amount of fluid that can be drained from the anterior chamber is about $0.25 \mathrm{ml}$. For 